\title{
Wind Farm-Battery Energy Storage Assessment in Grid-Connected Microgrids
}

\author{
Shafiqur Rehman ${ }^{1}$, Umar T. Salman ${ }^{2, *}$ and Luai M. Alhems ${ }^{1}$ \\ ${ }^{1}$ Mechanical Engineering Department, King Fahd University of Petroleum \& Minerals, Dhahran, 31261, Saudi Arabia \\ ${ }^{2}$ Electrical Engineering Department, King Fahd University of Petroleum \& Minerals, Dhahran, 31261, Saudi Arabia \\ ${ }^{*}$ Corresponding Author: Umar T. Salman. Email: g201706090@kfupm.edu.sa \\ Received: 10 May 2020; Accepted: 30 June 2020
}

\begin{abstract}
Renewable energy has received much attention in the last few decades and more investment is being attracted across the world to boost its contribution towards the existing energy mix. In the Kingdom of Saudi Arabia (KSA), many studies have been conducted on the potential of renewable energy sources (RES), such as wind, solar, and geothermal. Many of these studies have revealed that the Kingdom is blessed with an abundance of RES with wind energy being the best after solar. This paper presents an analysis of windfarm distributed generation (WFDG) for energy management strategy in the Eastern Province of KSA. The study investigates the possibility of partially sharing the load of the area from a wind farm of $100 \mathrm{MW}$ installed capacity. Furthermore, the effect of supplementing the WFDG with diesel generators is explored. Based on the historical wind resources and the load data, the cost of electricity is analyzed using a dynamic pricing system. Simulations are carried out using quadratically constrained program available in the General Algebraic Modeling System to obtain the operational cost of the WFDG needed to achieve the target. The dispatch of the battery energy storage system is analyzed during the 24 hours' simulation period. Results showed the overall quantitative responses of the microgrid on the demand, power exchange, and dynamic pricing across all scenarios. Additionally, the study showed that it is crucial to consider the operation of a microgrid at different sites independently. The performance analysis showed that a loss of power supply probability of less than $1 \%$ is achievable in all scenarios.
\end{abstract}

Keywords: Distributed generation; energy storage system; Eastern Province; renewable energy; windfarm; wind energy

\section{Introduction}

Wind, among other RE sources like solar, hydro, biomass, geothermal, etc. is the fastest-growing source in the world. The global cumulative wind power installed capacity reached $597 \mathrm{GW}$ at the end of the year 2018, an increase of $9.1 \%$ compared to 2017 [1]. In 2018 a total of $50.10 \mathrm{GW}$ of new capacity was added which was slightly less than that in $2017(52.552 \mathrm{GW})$. The report further mentioned that all wind turbines installed by the end of 2018 can cover close to $6 \%$ of the global electricity demand. The world is transforming, switching from fossil fuel-based power generation to clean and renewable sources of energy to minimize greenhouse gas emissions and safeguard the planet for future generations. Besides, there is a

This work is licensed under a Creative Commons Attribution 4.0 International License, which permits unrestricted use, distribution, and reproduction in any medium, provided the original work is properly cited. 
threat that the world's fossil fuel reserves will be depleted in the next 150 years [2]. Therefore, the need of exploring and deploying alternative, renewable, and clean sources of energy is fast-growing throughout the world. Accordingly, it is the vision of many countries to increase the penetration of renewable generation (RG) in their existing energy mix in the nearest future. Saudi Arabia, which is one of the leading fossil fuel suppliers in the world, is diversifying its existing energy portfolio by adding power generation through wind and solar energy sources. KSA has installed two wind turbines each of $2.75 \mathrm{MW}$ rated power at two different locations on an experimental basis to learn the wind power project development process and its integration with the grid. The nation has signed a contract, with consortia consisting of EDF France and MASDAR UAE, to develop a 400 MW installed capacity wind farm in Dumat AlJindal, Al-Jawf province, Saudi Arabia (see the site's view in Fig. 1). In the present scenario, despite a moderate population size of about 33 Million, it is consuming more fossil fuel for power production than the global average.

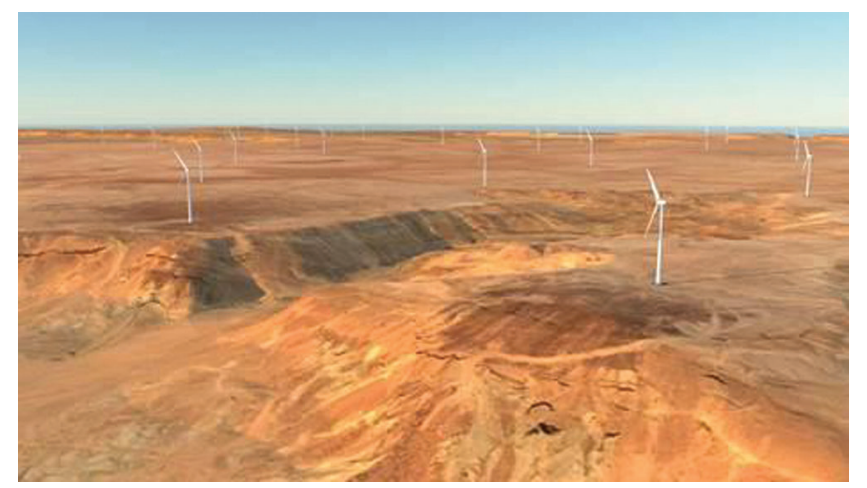

Figure 1: Wind farm

Due to the geographical location and harsh weather conditions, it consumes more electricity than any of the Gulf countries with a compound annual growth rate of 6 percent in the last 5 years [3]. On the power demand front, the residential sector accounts for the highest electricity consumption, representing about $70 \%$ with an annual growth rate of $14.8 \%$ [4], especially in summer when mostly all homes are on air conditioners.

In this paper, an analysis of the operational cost of WFDG of the type shown in Figs. 2 and 3 is carried out for energy sustainability in the Eastern region. In Scenario I, the microgrid is made of WFDG while in Scenario II, it is supplemented with diesel generators (DGs) and the optimal operational cost is computed in both the cases. The study investigates the possibility of partially meeting the load of residential buildings, hospitals, and government premises in selected areas. However, the wind farm is supplemented with battery energy storage systems (BESS) and the utility grid. Simulations are made using quadratically constrained program (QCP) available in the General Algebraic Modeling System (GAMS) to obtain the operational cost of the WFDG needed to achieve the targeted size of the wind farm. A regulated dynamic pricing market system is assumed for the present pricing analysis. Additionally, the state of charge (SOC), charging and discharging of energy storage is investigated.

The rest of the paper is organized as follows; Section 2 discusses related work, Section 3 presents the system configuration, wind turbine, the characteristics of the BESS, utility grid, and associated constraints, Section 4 covers the problem formulation and Section 5 presents the model for performance analysis of the results. Section 6 is devoted to the results and discussion, the results of the three sites and the Scenarios are compared in Section 7. Lastly, conclusions are presented in Section 8. 


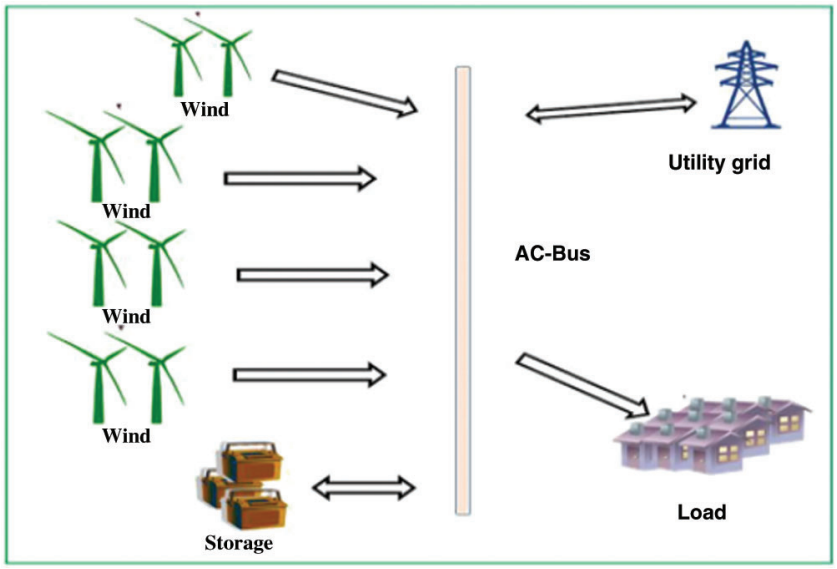

Figure 2: Microgrid with wind farm distributed generation (WFDG)

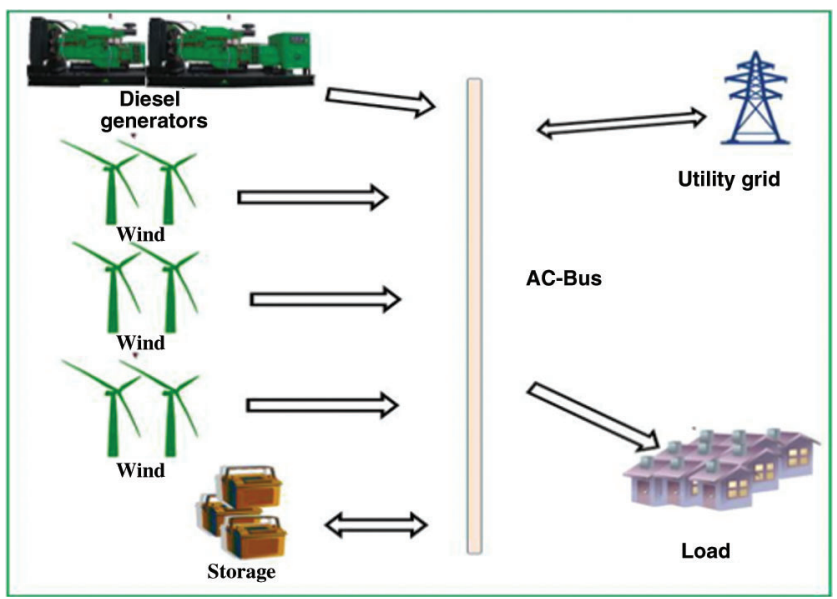

Figure 3: Microgrid with WFDG and diesel generators

\section{Related Work}

As part of the vision 2030 of KSA, it has proposed to increase its renewable portfolio; consisting of wind, solar PV, and solar thermal; by 50,000 MW [5]. In KSA, the electricity demand is constantly increasing every year and is expected to grow by a larger amount shortly due to the country's vision 2030 initiatives. Hence, to meet the growing power requirement through renewable energy sources (RES), the country has initiated research initiatives to help achieve this goal. As part of resource assessment, King Abdullah City for Atomic and Renewable Energy (KACARE) recently established 10 meteorological stations (90-meter-tall masts) to measure wind speed and direction at different heights and other meteorological parameters near ground level. KACARE team also installed 40 stations to monitor all the meteorological parameters including solar radiation for solar resource assessment around the country $[4,6]$. As reported in [6], the average wind speed in the Western region is about 7.0 to $7.5 \mathrm{~m} / \mathrm{s}, 5.0$ to 6.5 $\mathrm{m} / \mathrm{s}$ in the Central, and 7.5 to $8.0 \mathrm{~m} / \mathrm{s}$ in the Eastern area. These sites, as presented in [7] are located in the South, North, West, East, and central regions of KSA.

The possibility of harvesting and increasing the share of RES has been emphasized by the experts in the literature [8-12], while some others have discussed optimization, integration, policy, and control of these RES [13-18] for its efficient and effective utilization. Rehman et al. [12] and Salman et al. [16] evaluated 
the capacity values of both wind and PV power plants for an isolated mini-grid. Salman et al. [16] also investigated the effect of the probability of losing a large load and proposed a way to improve the stability of the grid of such fluctuations.

The authors in $[16,11]$ presented a method to integrate and investigated the effect of large-scale wind power penetration in the existing power grid of KSA. Different scenarios were tested using a power system operator's model and satisfactory results were obtained. Rehman et al. [9] conducted wind energy potential for a remote village in the northeastern region of Saudi Arabia. The study revealed that installing 30 wind turbines of 1.0 MW rated capacity each could potentially generate up to $88.0 \mathrm{GWh}$ of electricity each year at an average plant capacity factor of 33.5\%. Shahrani et al. [10] investigated the possibility of using Electric Vehicles (EV) for transportation and as energy storage to optimize the costs and fully utilize the available renewable energy.

A method for planning a hybrid wind-solar system for optimal power generation was studied in [13,18] and the energy storage capacity required for the efficient operation of the hybrid system was computed. The impact of introducing the RES into the power systems of KSA was investigated by Yasin et al. [14] by considering factors such as the Levelized cost of electricity (LCOE), operation and maintenance costs, reserved capacity, unit dispatching, dynamic and static security of the network. Twaha et al. [18] included field tariffs for optimal hybrid renewable distributed generation and ranking techniques. Their results suggested that the model is applicable and suitable for KSA climatic conditions. Eroshenko et al. [19] optimized the allocation of wind farms in areas with multiple power systems using the distributional robust model found it to be very effective.

In the recent past, some studies predicted the renewable potentialities of wind power in KSA. It was proposed that wind energy resources could be one of the most promising and economical sources of energy in the country [20-26]. Many of these studies discussed the wind power resources and assessment for different regions based on seasonality, cost, variability, wind characteristics, etc. The study [20], investigated the output of the wind energy with a diesel generator and BESS backup and showed that the diesel generators will support the hybrid system for only about $17.5 \%$ for $150.0 \mathrm{~kW}$ power generated from the wind with the BESS having an immunity period of three days. Abbadi [22] carried wind power resource assessment at five locations in KSA by estimating the annual energy yield from the chosen wind turbines. Rehman et al. [25] presented the cost of wind power generation at twenty locations based on three sizes of wind machines and also developed the wind duration curves and estimated the cost of wind energy per kWh. The study in [26] found that the ESS can significantly offset the uncertainties of wind power but limited by rated capacity and time of discharge.

Atherton et al. [27] investigated the relationship between the size of a wind farm, wind farm variability, and ESS. The study found that larger wind farms require smaller proportion of ESS capacity compared to smaller wind farms. The payback period for investment on ESS is longer in small wind farms than in large. In [28], the authors compared the economic and technical performance of two energy storage in a large wind farm, the study found that the pumped storage has better economic performance than the BESS due to the short discharge time in BESS. Furthermore, the authors reported that an optimized generation could reduce power output variability but can increase profitability of the wind farms. Song et al. [29] investigated the economic impact of reusing a BESS in wind farms and stated that it is not profitable to invest in a used battery for wind farms given the present prices of the wind energy. However, it may become profitable in the future if the prices of wind energy improve. Salman et al. [30] computed the monthly requirement of BESS in a wind power penetrated microgrid situated in the Eastern Province of KSA. An interesting approach was presented by Phan et al. in [31] investigated the relationship between the rate of charge/discharge of the battery and the operating cost of the microgrid using genetic algorithm and particle swarm optimization techniques. The study showed that the operating 
cost of a microgrid decreases with an increase in the rate of charge/discharge and, the genetic algorithm technique performed better than particle swarm optimizer. Moreover, findings stated that the use of battery and weather data scaling factors could cause a reduction in the operating cost of a microgrid. Similar findings were also reported by Salman et al. in [32], where the authors showed that scaling up the size of the RES under dynamic pricing could potentially reduce the cost of electricity. However, both studies did not consider the effect of having different distributed generations and location potential.

None of the studies in the past, suggested a $100 \%$ penetration of wind power into the existing energy mix portfolio with the BESS requirement to meet the load profile of the Eastern Province of KSA. Therefore, the issues which are addressed in this study are as follows:

- Compute the operation cost of the wind farm under each Scenario and cases, as stated.

- Investigate the economic and technical impact of the wind farm on the optimal operation of the BESS and other distributed generation considering wind power potentialities.

- Assess the reliability effect due to the addition of diesel generators and number of generators.

- Conduct performance assessment of the WFDG and verify which configuration is better.

\section{System Configuration}

In this paper, grid-connected microgrids of the types shown in Figs. 2 and 3 for Scenarios (I \& II) are presented. In Scenario I, the wind is the only source to be used to supply the load as much as possible. In case of shortages in power from wind, the BESS and the grid can serve as backup sources. On the other hand, when the energy production from the wind exceeds the consumption at any point of time, the excess energy is sold to the grid at higher tariff (if applicable) or can be diverted to charge the BESS if the tariff is low. In Scenario II, the diesel generators act as another power source, serving as a back-up power in addition to the BESS and the grid. These back-up sources act and serve the same purpose as in Scenario I.

\subsection{Data Description}

The data used in this study is obtained from the Eastern Province of KSA. The locations of the chosen sites are shown in Fig. 4. The three stations considered here are Al-Al-Dhahran, Al-Ahsa, and Al-Al-Khafji. The station in Al-Al-Dhahran is located at N26.500-E50.000, while the Al-Al-Khafji station at N28.500E48.125 and Al-Ahsa at N25.500-E49.375. The hourly mean wind speed data corresponding to 17th July

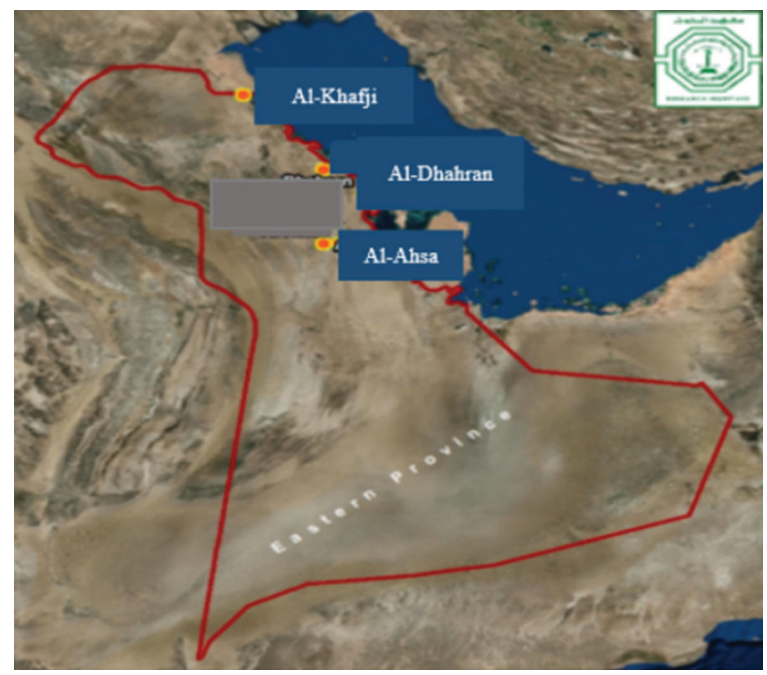

Figure 4: Windographer station, Easter Province, KSA 


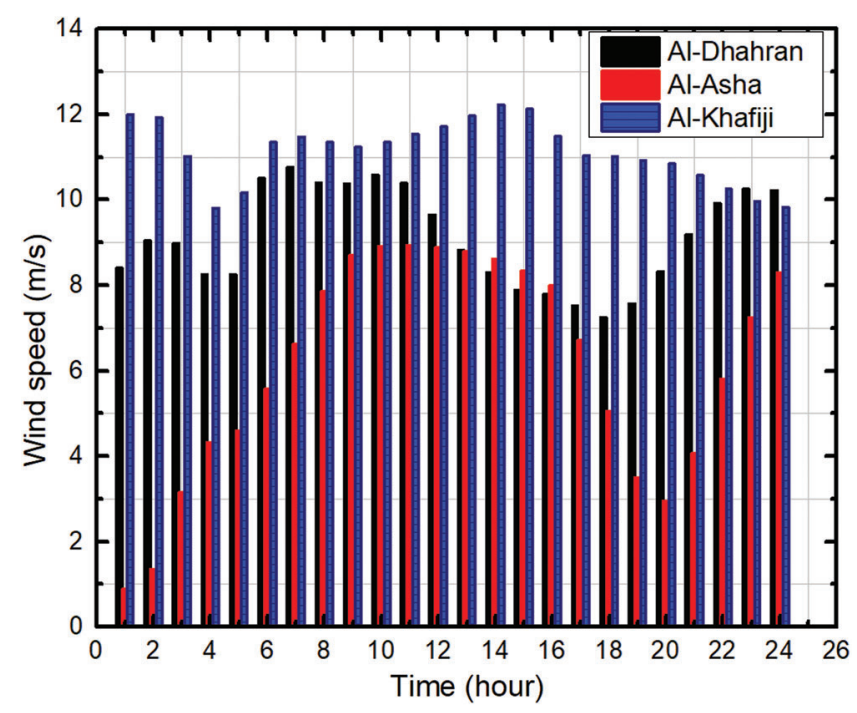

Figure 5: Wind speed of three sites in Eastern Saudi Arabia

Table 1: Values of parameters used in microgrid model

\begin{tabular}{lllll}
\hline Power coefficient & Air density & Rotor area & BESS energy capacity & Wind power \\
\hline 0.45 & $1.18 \mathrm{k} / \mathrm{m}^{3}$ & $3019.07 \mathrm{~m}^{2}$ & $100 \mathrm{MWh}$ & $1000 \mathrm{~kW}$ \\
\hline
\end{tabular}

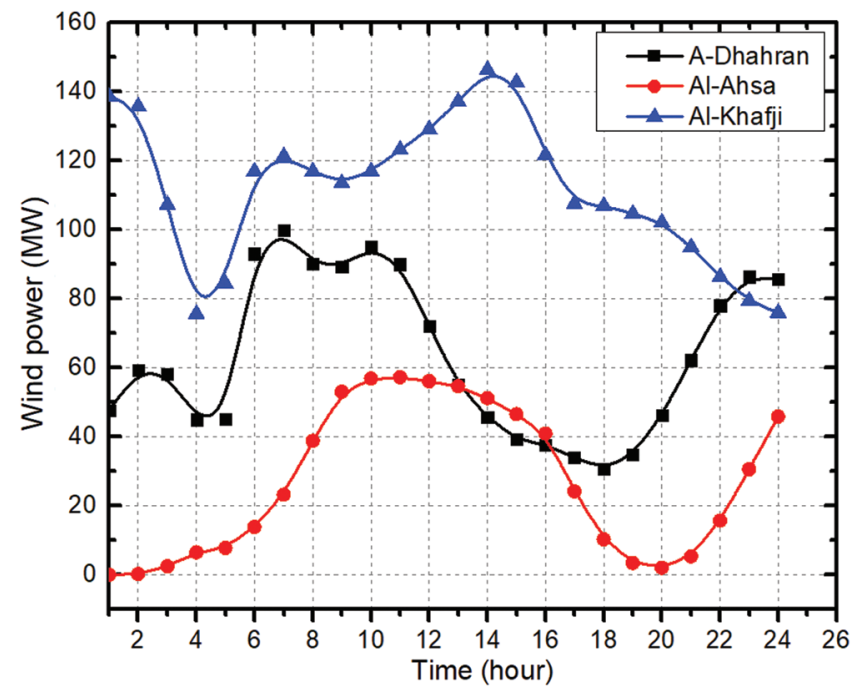

Figure 6: Diurnal variation of available wind power at selected sites

2018 is used for the simulation (Fig. 5). The data corresponds to the highest monthly wind speed recorded for the year 2018 and measured at a height of $50 \mathrm{~m}$. The average air density at the site is considered as $1.18 \mathrm{Kg} / \mathrm{cm}^{3}$ while the average ambient temperature is found to be $43^{\circ} \mathrm{C}$. The maximum value of the power coefficient is taken as 0.45 . All of these values, along with the wind turbine rotor swept are summarized in Tab. 1 and the calculated wind power is shown in Fig. 6. 


\subsection{Wind Energy System}

The wind farm considered in this study, consists of 100 wind turbines each of $1000 \mathrm{~kW}$ rated capacity to achieve a total installed capacity of the wind farm of 100.0 MW. To compute the power output of each turbine, Eq. (1) is used. The power generated from a wind turbine is directly proportional to the rotor swept area, the cube of the wind speed, air density, and the power coefficient, as expressed in Eq. (1).

$P_{w t}=12 \times C_{\max } \times \rho \times A_{f} \times V^{3}$

where, $A_{f}$ is the rotor swept area of the wind turbine, $\rho$ is the air density, $C_{\max }$ is the power coefficient, and $V$ is the wind speed.

\subsection{Battery Energy Storage System}

The operation of the BESS is such that it supplies the power to the grid when the power production from the wind farm is not sufficient to meet the load demand. On the other hand, the BESS is charged whenever there is surplus power available from the wind farm. The BESS capacity for charging, termed as state of charge $(S O C)$, is expressed as given in Eq. (2) [33].

$S O C=\frac{C(t)}{C_{r e f}}$

where $C_{r e f}$ is the reference capacity of the BESS and $C(t)$ is the capacity of the BESS at present time, $t$. During the charging process, the previous state of charge, $S O C(t-1)$ is related to the instant $\operatorname{SOC}(t)$ during the time interval $(t-1)$ to time $\mathrm{t}$ by Eq. (3). The measurement of SOC of the BESS is critical in its operation and some important parameters of the BESS can be expressed in terms of the SOC [34-35], as follows:

$\operatorname{SOC}(t)=\operatorname{SOC}(t-1)+\frac{P_{w t}+P g(t)+P d(t)}{C_{r e f}} \Delta t$

\subsection{Loads Description}

The load includes the residential, hospitals, offices, and government institutions connected to the distribution networks. The BESS is also classified as a load during the charging operation. The power converters are used as interconnection interface for RES and BESS with the grid and detail analysis of the role of these converters is not discussed. Furthermore, no assumption is made for the frequency and voltage of the microgrid as these are controlled by the utility grid [36]. The load profile for the Al-Dhahran city and the cost of energy in $\$ / \mathrm{kWh}$ is shown in Fig. 7 and is considered the same for all the locations.

\subsection{Utility Power}

The configuration adopted in this study, electric power is exchangeable between the utility grid and microgrid at a predefined cost. Power is to be purchased from the utility grid when the electric power output from the wind sources is insufficient to meet the load demand. However, when the output from the wind sources exceeds the load consumption, the excess power will be sold back to the grid at high tariff or will be used to charge the BESS. The simulations are carried out under a dynamic tariff system. In this case, the price of the electricity is dependent on the time of use (TOU). The unit price of electricity is given in Fig. 7. However, the average cost is considered as 2.48 cents $/ \mathrm{kWh}$ (in a regulated fuel price) and about 9.45 cent $/ \mathrm{kWh}$ (in deregulated fuel price) during the summertime in KSA [35]. 


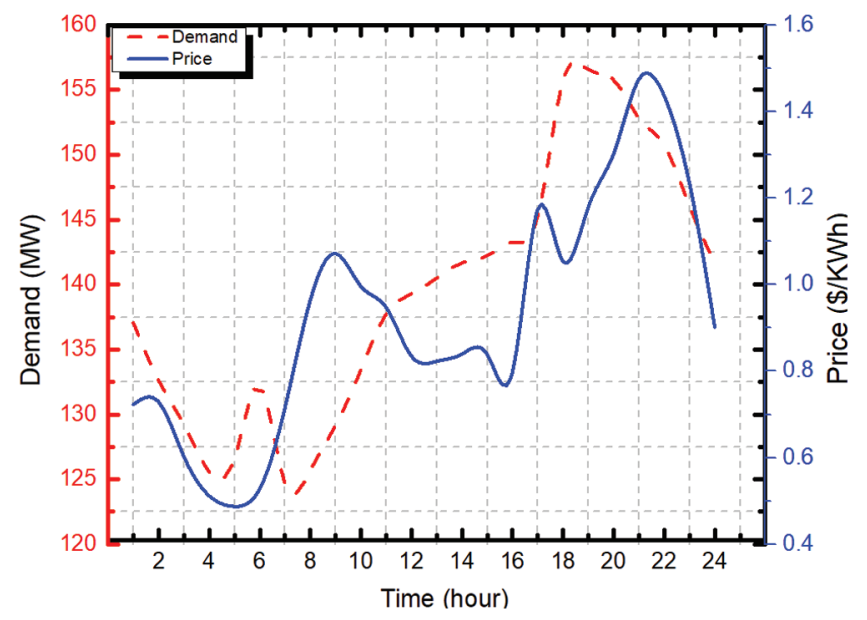

Figure 7: Load demand and cost for Al-Dhahran in summer (17th July 2018) [7]

\section{Problem Formulation}

In this section, the objective function of the proposed energy sustainability techniques and the associated constraints are explained.

\subsection{Objective Function}

The objective of the proposed strategy is to optimize the cost of operation of a grid-tied microgrid made up of windfarms of the types shown in Figs. 2 and 3 in the Eastern Province of KSA. The costs of wind turbines, generators, power converters, and installation of the microgrid are not included in this study. However, the maintenance cost of diesel generators and the wind turbines and battery replacement are included. Furthermore, the cost of wind power generation is very small due to freely available wind resource and consequently the it is the cheapest source of energy in this model.

\subsubsection{Scenario I-Mathematical Equations}

In this scenario (Fig. 2), the operation cost of the WFDG is optimized. In this case, the objective function is to minimize the total cash flow (TCF) which is the operational cost during the studied period. The TCF, as expressed in [38], is defined in terms of paid cash (PC) and received cash (RC). In this study, the PC is designated positive while the $\mathrm{RC}$ as negative. The objective function is then expressed as in Eq. (4):

$T F C=\min . \sum_{0}^{T} R C(t)+P C(t)$

where the $\mathrm{RC}$ is the total profit made from the sales of excess power to the utility and is expressed as:

$R C(t)=P_{\text {grid }}(t) \cdot U_{p m}(t) \cdot t$

Noting, that the power exported to the grid at any time $t, P_{\text {grid }}(t) \leq 0$ and $U_{p m}$ is the unit price of electricity from the microgrid. To express PC, the cost of electricity consumed from the grid and the amount spent on battery replacement are included, as expressed in Eq. (6).

$P C(t)=P_{\text {grid }}(t) \cdot U_{p g}(t) \cdot t+C_{B R}(t)$

where $U_{p g}$ is the unit price of electricity from the grid to the microgrid and $C_{B R}$ is the battery replacement cost. Therefore, Eq. (4) becomes: 
$T F C=\min . \sum_{t=1}^{T}\left[P_{g}(t) \cdot U_{p m}(t) \cdot t+P_{\text {grid }}(t) \cdot U_{p g}(t) \cdot t+V W C(t)+C_{B R}(t)\right]$

The computation of battery replacement cost, $C_{B R}$ requires the knowledge of battery change in state of health $(\triangle \mathrm{SOH})$ as well as the aging coefficient of $(\mathrm{z})$ [38]. This is expressed as follows:

$C_{B R}(t)=C_{B I} \cdot \frac{\Delta S O H(t)}{1-S O H_{\min }}$

where $\triangle \mathrm{SOH}_{\min }$ is the minimum state of health of the battery and $C_{B I}$ is the battery's investment cost. If we assume that the $\triangle S O H(t)$ is significantly small and approximately equal to $1-S O H_{\min }$ for all time $t$. Then from (7) and (8), one get;

$C_{B I} \approx \sum_{t=1}^{T} C_{B R}(t)$

The last term in Eq. (7) is replaced by $C_{B I}$ and thus $S O H(t)$ and $C_{B R}(t)$ are not measured instantaneously. However, the effect of $C_{B R}$ has a little comparative significance on TFC (Eq. (7)) because the same assumption applies to all of the Scenarios. With this assumption and based on the relationship between SOC and SOH described in [34], the value of $S O H(t)$ is perceivable.

\subsubsection{Scenario II-Mathematical Equations}

In scenario II, the WFDG microgrid is supplemented with four diesel generators (Fig. 3), and the operation cost is minimized. The objective function is formulated as given by Eq. (11). In this case, TCF includes the operating cost of the DGs and $C D G$ is the operation cost of microgrid distributed generators, $W R C$ is wind-related cost, $R C$ is the cost or revenue of the exchanged power imported from the main grid or exported to it. The operation cost of microgrid's diesel generators is calculated using the Eq. (9), where $a_{i}, b_{i}$, and $c_{i}$ are generator cost constants.

$C D G=\sum_{t=1}^{T} \sum_{i=1}^{T}\left[a_{i} P^{2}{ }_{i, t}+b_{i} P_{i, t}+c_{i}\right]$

Here $i$, is the unit index, $I$ is the number of units, $t$ is the hour index, $T$ is the number of hours. The quadratic function has been used to calculate the cost function of the generator because of the nonlinearity of Eq. (9) which gives accurate results. The cost of imported power or revenue accrued when power is exported from the main grid is computed using Eq. (5). Here, it is noted that the value of the objective function is more when power is imported and less when power is exported. In some studies, the cost of wind power is neglected. However, in this study the related cost associated with wind power curtailment at any time, $t$ is given by Eq. (10). In this equation, $V W C$ is the value of wind curtailment and $P_{w t}$ is the wind power generation at time $t$.

$W R C=\sum_{t=1}^{T} V W C \times P w c t$

It is seen that the $V W C$ parameter appears in both optimization equation of Scenarios I and II.

$T F C=\min . \sum_{t=0}^{T} R C(t)+P C(t)+C D G$ 


\subsection{Constraints Explained}

\subsubsection{Power Balance Constraint}

The power demand should be supplied from a combination of three options, which are the grid, the wind farm, and the BESS. The power balance constraint requires that:

$P d(t)=P w t(t)+P g(t)+P b(t)$

where $\operatorname{Pd}(\mathrm{t})$ is the demand at time $t$ and $P w t(t)$ is the wind turbine power at time $t$. This equation can be formulated in a different way as follows:

$P_{d}(t)+P_{c h}(t)=P w t(t)+P g(t)+P_{d i s}(t)$

where $P_{c h}(t)$ and $P_{d i s}(t)$ are the components of the BESS during charging and discharging operating respectively.

\subsubsection{Battery SOC Constraint}

The manufacturers, usually provide the maximum and minimum charge/discharge currents and so must be considered [38]. The minimum SOC of the battery should not go below its safe level otherwise this will cause deep discharge which can shorten the life of the battery [38]. Therefore, the battery SOC should be bounded as per Eq. (14).

$S O C_{\min } \leq S O C(t) \leq S O C_{\max }$

\subsubsection{BESS Power Output}

$P_{b \min } \leq P_{b}(t) \leq P_{b \max }$

Furthermore, the constraint on variation of SOC must satisfy:

$\Delta S O C_{\min } \leq \Delta S O C(t) \leq \Delta S O C_{\min }$

\subsubsection{Battery Aging Constraint}

The battery aging constraint requires the state of health $(\mathrm{SOH})$ to be limited to:

$S O H(t) \geq S_{\min }$

\subsubsection{Grid Power Constraint}

The grid power constraint requires the grid exchange the power in the range as stated in Eq. (18):

$P_{\text {grid }}^{\min } \leq P_{\text {grid }}(t) \leq P_{\text {grid }}^{\max }$

Furthermore, the received power from the main grid $P_{\text {grid }}^{\max }$ must satisfy the conditions in Eqs. (19) and (20). In this study, the value of $P_{\text {grid }}^{\max }$ is considered as $100 \mathrm{MW}$.

$0 \leq P_{\text {grid }}^{\max } \leq P_{d}^{\text {peak }}$

$P_{\text {grid }}^{\min }=-P_{\text {grid }}^{\max }$

\subsubsection{Generator Constraints}

The generator units have different characteristics and constraints. The constraint on a generator unit $i$, is expressed as per Eq. (21). Where $P_{i}(t)$ is the generator $i$ output at time $t$ lying between $P_{i}^{\min }$ and $P_{i}^{\max }$ which are minimum and maximum output of unit $i$ respectively. 
$P_{i}^{\min }(t) \leq P_{i}(t) \leq P_{i}^{\max }$

Ramp up $\left(R U_{i}\right)$ and ramp down $R D_{i}$ are two other constraints limiting the rate of increasing and decreasing of the output power of a diesel generator unit. The output power of a unit $i$ should not increase or decrease freely. The constraints defined to represent these limits are given in Eqs. (22) and (23).

$P_{i}(t)-P_{i}(t-1) \leq R U_{i}$

where $R U_{i}$ is the ramp up rate of unit $i$.

$P_{i}(t)-P_{i}(t-1) \leq R D_{i}$

where $R D_{i}$ is the ramp down rate of unit $i$.

\section{Performance Analysis}

The performance analysis of a microgrid system could be measured based on its reliability and cost of electricity per MWh $[39,40]$. The reliability analysis is carried out statistically, based on loss of power supply probability (LPSP). The LPSP of the microgrid measures the chances of time horizon within which the microgrid total distributed generation will not be able to meet the demand. It is the ratio between the energy shortage and the total energy demands of the load for a long period of time and, usually, it ranges from 0 to 1 [41]. In the literature, it is also referred to as the loss of power probability or the loss of load probability [42]. The LPSP is calculated using Eqs. (24) and (25), given in [37] for Scenario 1 and Scenario 2; respectively.

$\operatorname{LPSP}=\frac{\sum_{t=1}^{T} P_{d}(t)-P_{w}(t)-P_{\text {grid }(t)}-P_{b}(t)}{\sum_{t=1}^{T} P_{d}(t)}$

$\mathrm{LPSP}=\frac{\sum_{t=1}^{T} P_{d}(t)-P_{w}(t)-P_{\text {grid }}(t)-P_{i(t)}-P_{b}(t)}{\sum_{t=1}^{T} P_{d}(t)}$

\section{Results and Discussion}

In this section, the results are presented and discussed for three sites. The two scenarios are analyzed and compared for each site.

\subsection{Simulation Results for Al-Dhahran Site}

The optimal operation costs for the two scenarios are presented in Tab. 2. The operation cost of WFDG in Scenario I is $\$ 24,633.2$, while that of scenario II is $\$ 60,098.4$. These are the minimum amount required to operate the microgrid for 24 hours under different scenarios. The value obtained for the diesel-based WFDG exceeds that of non-generator based WFDG by about 144\%. This is far from expectation because the maintenance costs of the diesel generators are quite high compared to the BESS. Furthermore, the

Table 2: Optimal operation cost and BESS power for Al-Dhahran

\begin{tabular}{lll}
\hline Parameter & Scenario I & Scenario II \\
\hline Cost of operation $(\$)$ & $24,633.20$ & $60,098.40$ \\
Total BESS discharge (MW) & 236.40 & 30.90 \\
Total power consumed by BESS (MW) & 246.40 & 109.70 \\
\hline
\end{tabular}




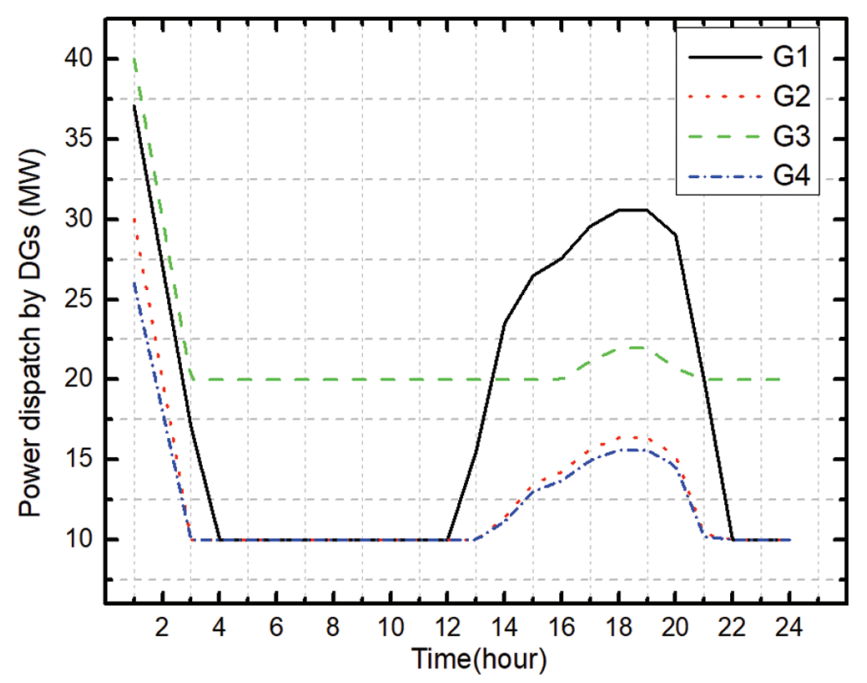

Figure 8: Hourly dispatch of diesel generators-Al-Dhahran

operational cost of $\$ 60,098.4$ also includes the maintenance and BESS cost, since the BESS also operates for a few hours in Scenario II. Fig. 8 explains the power dispatched by the diesel generators at different hours of the day. It can be observed that the generators operate at their minimum ratings during the hours of low demand. At hour 12, the generators start dispatching higher power as the demand starts increasing from 12 hours onwards.

Tab. 2 also shows the total power consumed by BESS to charge the batteries. Of course, one expects that amount recorded in the Scenario I to exceed that of in Scenario II since the BESS discharges for more hours in Scenario I than in Scenario II. Figs. 9 and 10 show the hourly dispatch of the BESS in the two scenarios. It is noted that the dispatch of BESS in the Scenario I is higher compared to that in Scenario II. It is due to the fact that the BESS discharges for more than 9 hours in Scenario I and for only 3 hours in Scenario II. The discharge in both cases occurred during the hours of high demand and high prices of the electricity from the grid. However, charging occurs during low demand hours or low electricity price in both Scenarios. The SOC

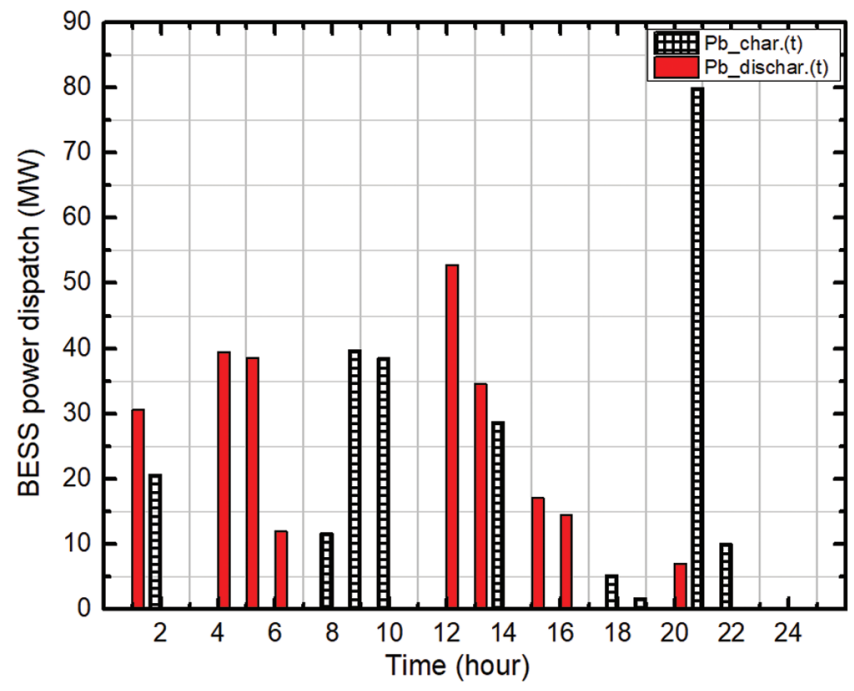

Figure 9: Hourly dispatch of BESS in Scenario I-Al-Dhahran 


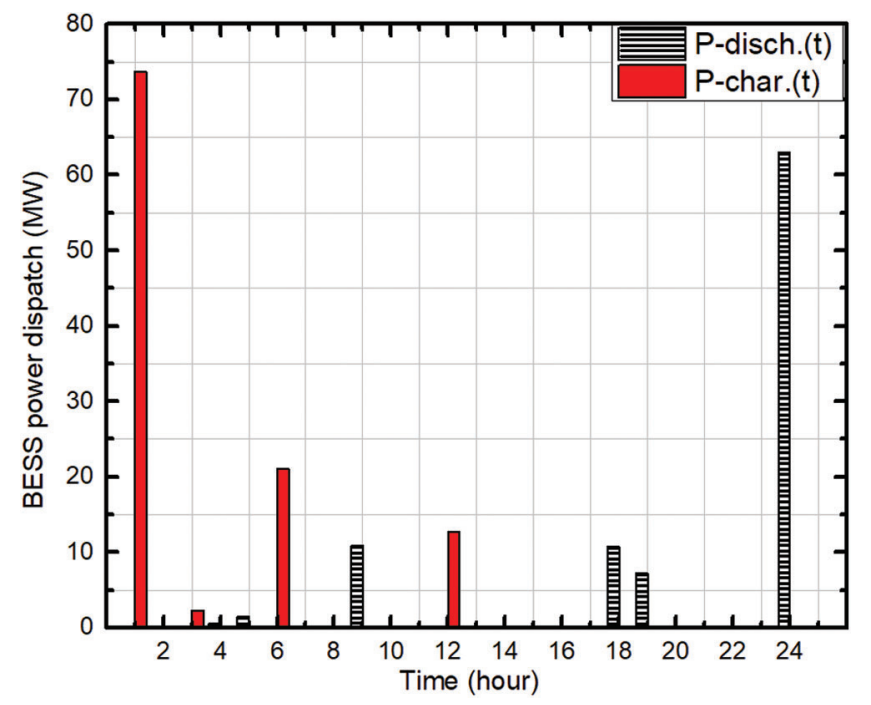

Figure 10: Hourly dispatch of BESS in Scenario II-Al-Dhahran

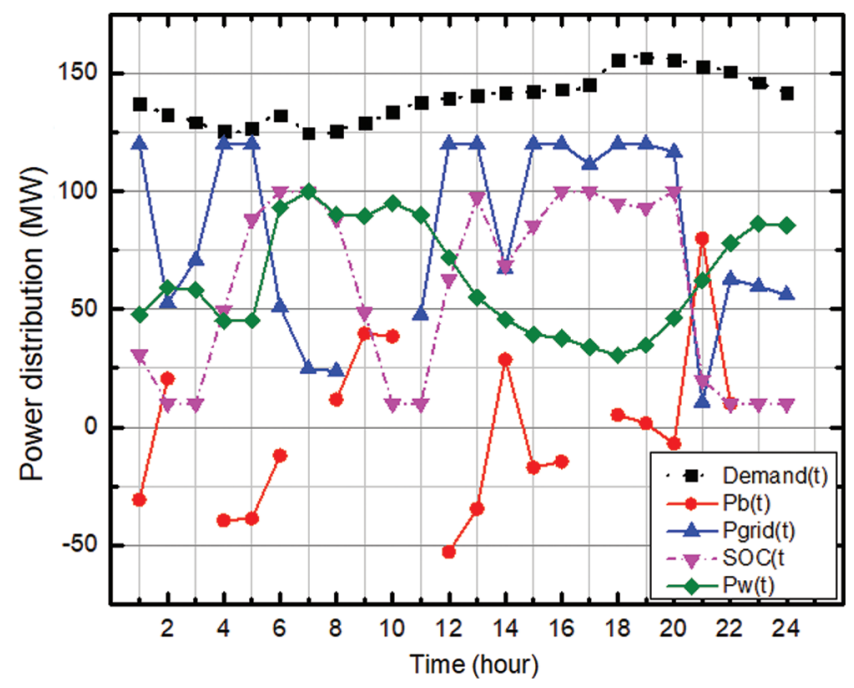

Figure 11: Power distribution in the scenario I-Al-Dhahran

of the BESS in both Scenarios is shown in Figs. 11 and 12 together with power supplemented by other sources. The SOC of the BESS varies according to the power demand and wind power availability. Furthermore, the microgrid sells power to the grid between hours 7 and 12 due higher availability of wind power.

\subsection{Simulation Results for Al-Ahsa Site}

The optimal costs of operation recorded for Scenarios (I and II) are \$25,175.9 and \$72,113.0; respectively (Tab. 3). The cost of operation recorded in this case is comparable to what was obtained in Al-Dhahran micro-grid (Scenario I). In Scenario II, the operation cost is found on the higher side $(16.7 \%)$. The BESS power dispatch for the two Scenarios is shown in Figs. 13 and 14. Significant discharge is observed between hours 3 and 6 (Fig. 13) and the discharge rate is high in Scenario I compared to that of Scenario II (Fig. 14). Similarly, at hours 16, 17, and 18, the charging of BESS in 


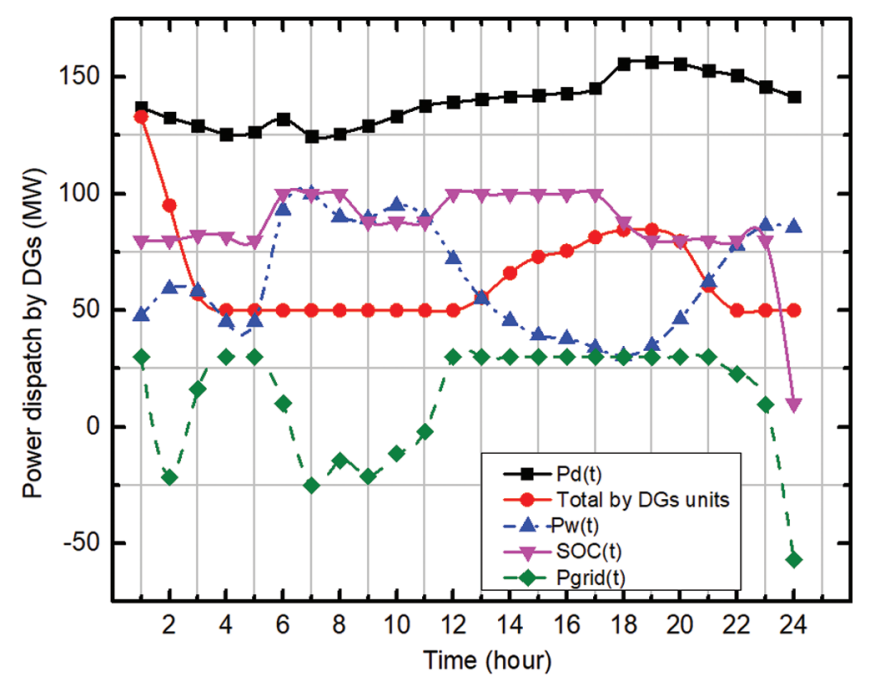

Figure 12: Power distribution in scenario II, Al-Dhahran

Table 3: Optimal operation cost and BESS power for Al-Ahsa

\begin{tabular}{lll}
\hline Parameter & Scenario I & Scenario II \\
\hline Cost of operation $(\$)$ & $25,175.90$ & $72,113.00$ \\
Total BESS discharge (MW) & 160.00 & 99.00 \\
Total power consumed by BESS (MW) & 180.00 & 115.80 \\
\hline
\end{tabular}

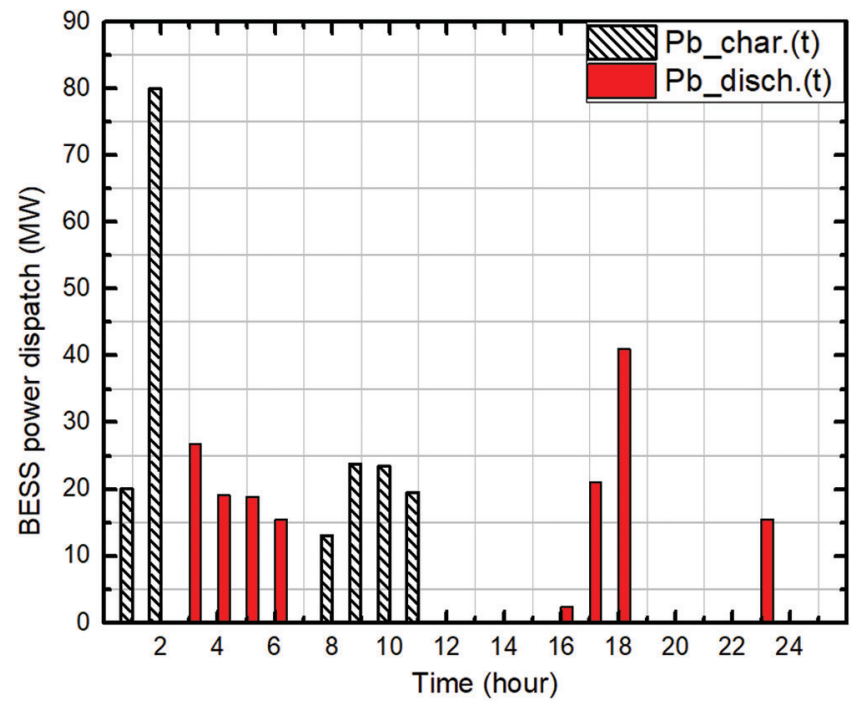

Figure 13: Hourly dispatch of BESS in Scenario I, Al-Ahsa

Scenario I is higher than Scenario II. This shows that the BESS is efficiently utilized in Scenario I than that in Scenario II. In Fig. 15, the power distributed by the different sources is depicted. It is seen that more power is consumed from the mini-grid with power consumption reaching the allowable limit of $100 \mathrm{MW}$ most of the time. However, from 11th onwards to 16th hours, the consumption from the grid dropped slightly because of 


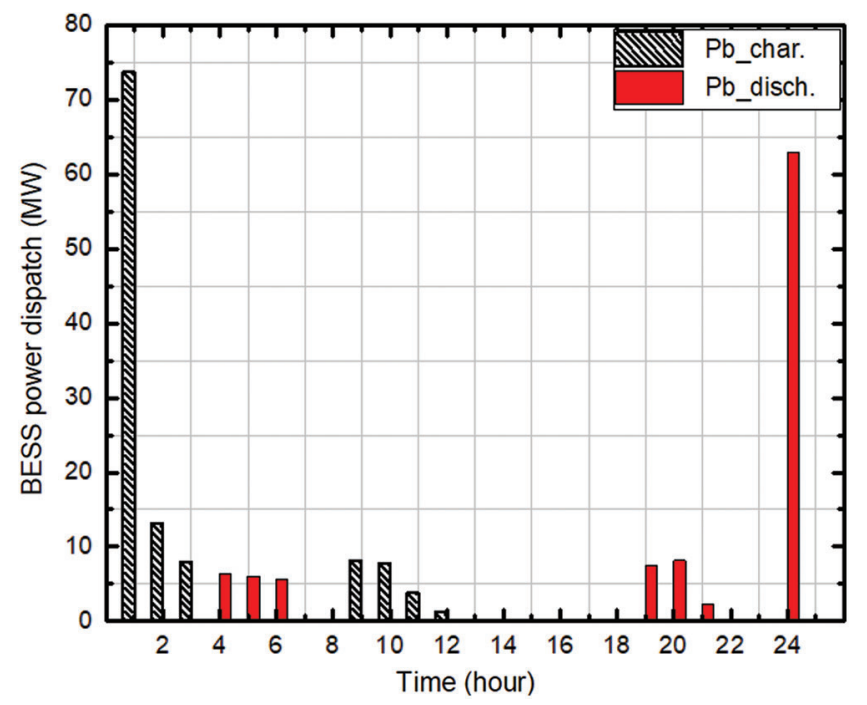

Figure 14: Hourly dispatch of BESS in Scenario II, Al-Ahsa

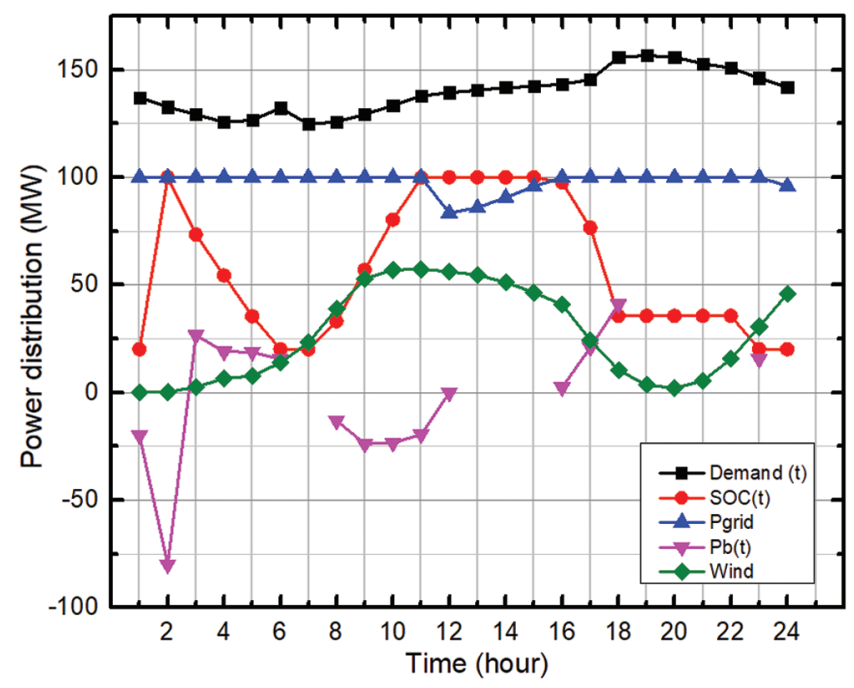

Figure 15: Power distribution in the Scenario I, Al-Ahsa

increased wind power generation. This shows that the micro-grid at Al-Ahsa site requires more power from the mini-grid due to lower wind potential compared to Al-Dhahran. It is further observed that the power is not sold to the grid in both Scenarios (I and II) in Al-Ahsa and the battery power is seen to being consistently discharged in Scenario I.

The output power from generators in Scenario II (Al-Ahsa) is presented in Fig. 16. It is noted that the generators' output power dropped between hours 8 and 16. The generators' power increased between 17 and 22 to compensate for the low output from the wind and supplemented the high demand during these hours. The generators in Al-Ahsa are more engaged during early hours of the day than that at Al-Dhahran. Generators G1 and G3, at Al-Ahsa site, generate slightly more power, above their minimum values, between hours 4 and 16 after which all the generators contribute more to the dispatched power (Fig. 16). This early dispatch of G1 and G3 generators occurs because of the lower output power from the wind farm during these hours. As observed from Fig. 17, the wind and the diesel generators contributed a 


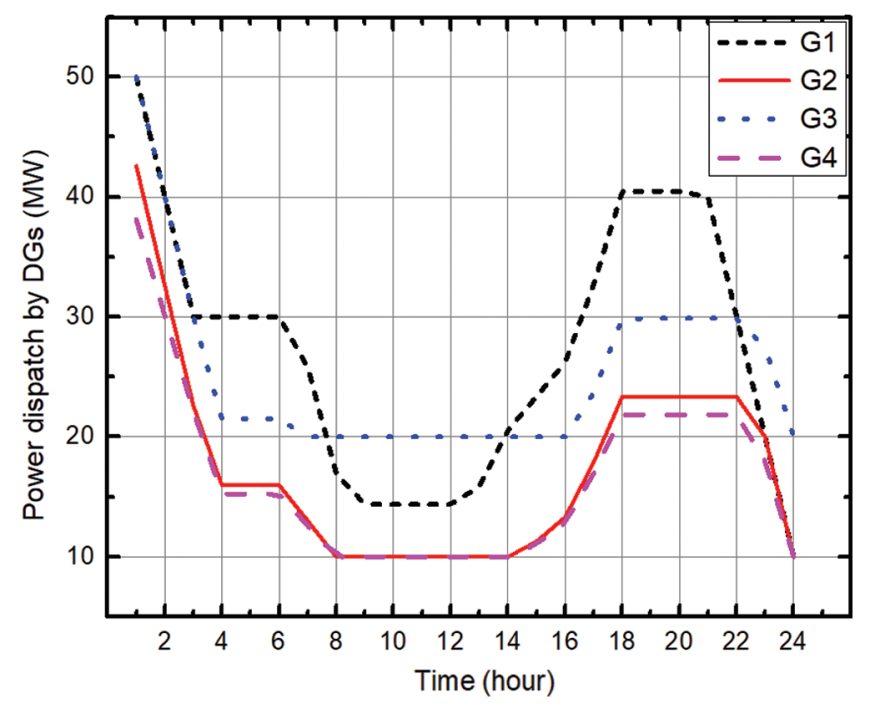

Figure 16: The hourly dispatch of the diesel generators, Al-Ahsa

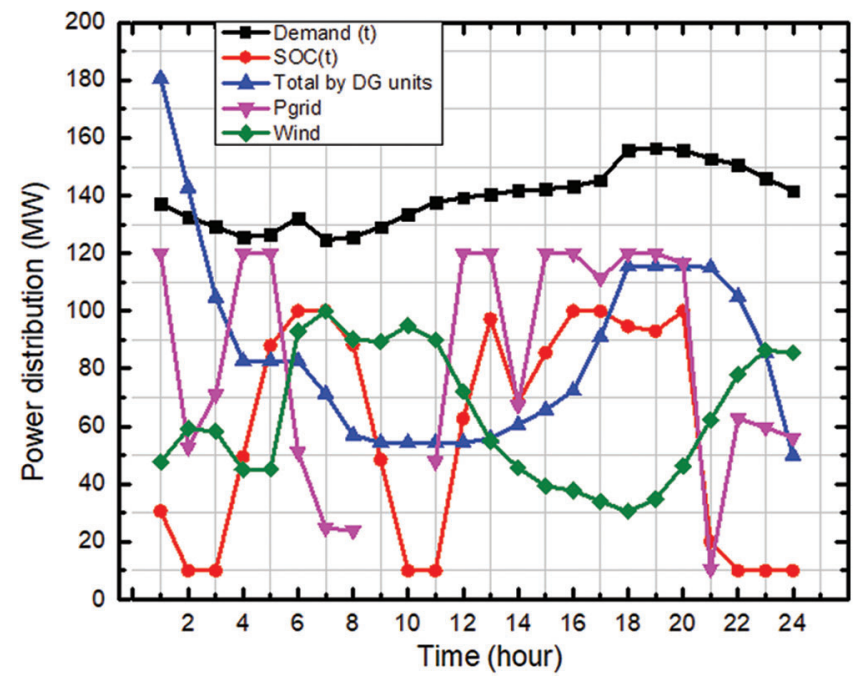

Figure 17: Power distribution in the Scenario II-Al-Ahsa

substantial part of the power during the 24 hours of operation. However, the mini-grid and the battery also supplied the power intermittently, as noted in Fig. 17.

\subsection{Simulation Results for Al-Khafji Site}

The minimum operating costs for a microgrid in Al-Khafji site for Scenarios I and II are \$23,000 and $\$ 40,177.6$ respectively (Tab. 4). The operation costs for Al-Khafji are less than those for Al-Dhahran and Al-Ahsa sites (Tabs. 2 and 3). The BESS dispatch, for the two Scenarios in Al-Khafji, is shown in Figs. 18 and 19; respectively. It is observed that the discharge power from BESS in both Scenarios is less than that in Al-Dhahran and Al-Ahsa microgrids. Furthermore, in Scenario II of Al-Khafji microgrid, the generators remain shut down or operated at the minimum conditions for most of the time except between hours 18 and 24 when only two generators, (G1 and G3), supplied little powers, as shown in Fig. 20. However, a little amount of power is supplied by BESS between hours 21 and 23 (Fig. 19). Moreover, a 


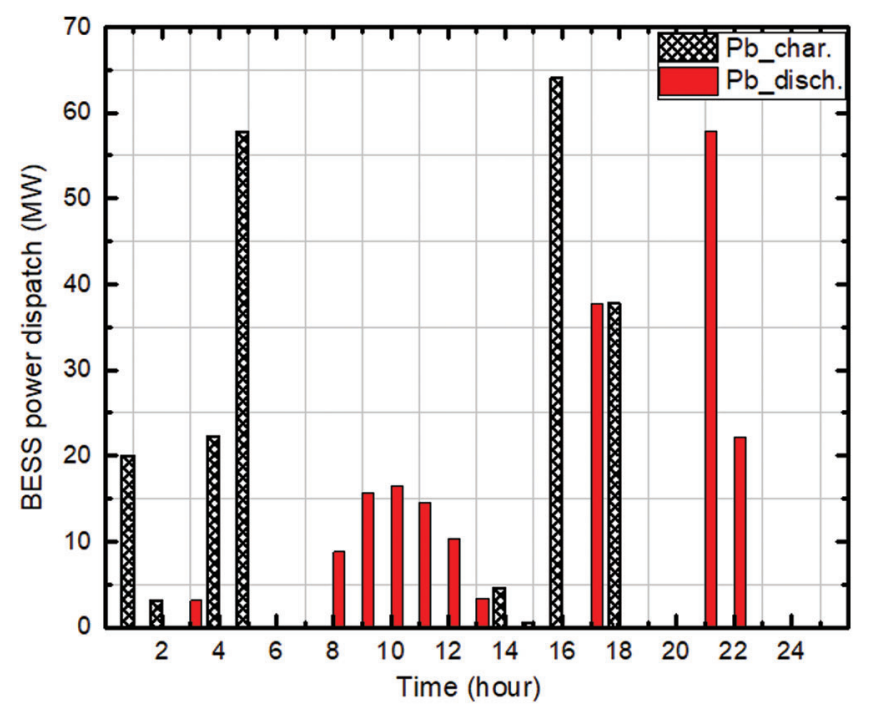

Figure 18: Hourly dispatch of BESS in Scenario I, Al-Khafji

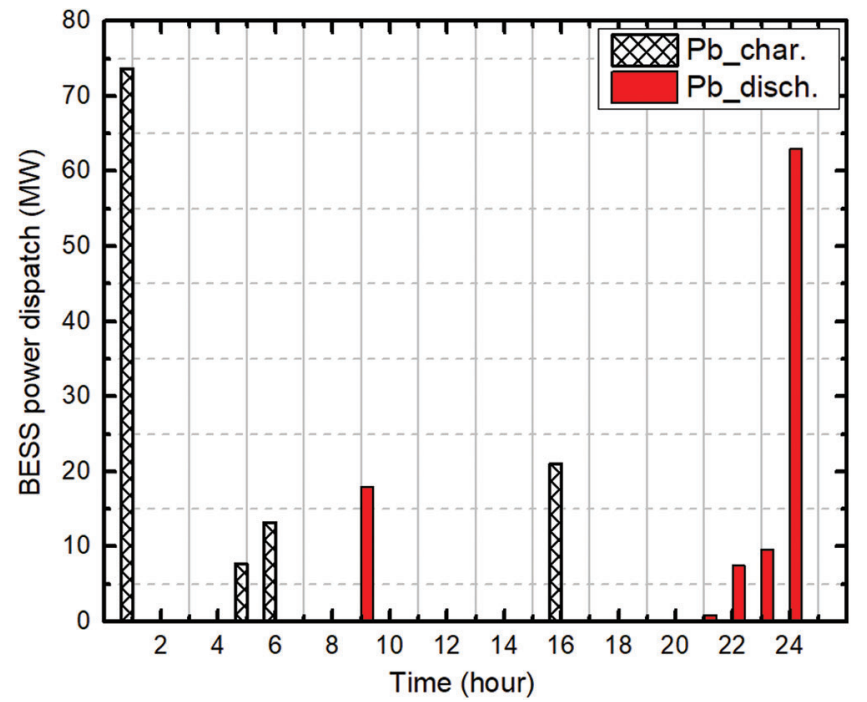

Figure 19: Hourly dispatch of BESS in Scenario II, Al-Khafji

Table 4: Optimal operation cost and BESS power for Al-Khafji

\begin{tabular}{lll}
\hline Parameter & Scenario I & Scenario II \\
\hline Cost of operation (\$) & $23,000.0$ & $40,177.6$ \\
Total BESS discharge (40 MW) & 190.1 & 99.0 \\
Total power consumed by BESS (MW) & 210.1 & 115.8 \\
\hline
\end{tabular}

little power is sold to the grid in Scenario II of Al-Khafji, between hours 2 and 15, (Fig. 22). The SOC of the BESS is observed to be high for most of the time in Scenario II (Fig. 22) compared to Scenario I (Fig. 21). The simulation results in Al-Khafji micro-grid indicate that the site has abundant wind power potential and has the strongest feasibility for wind farm deployment of the type proposed in this study. 


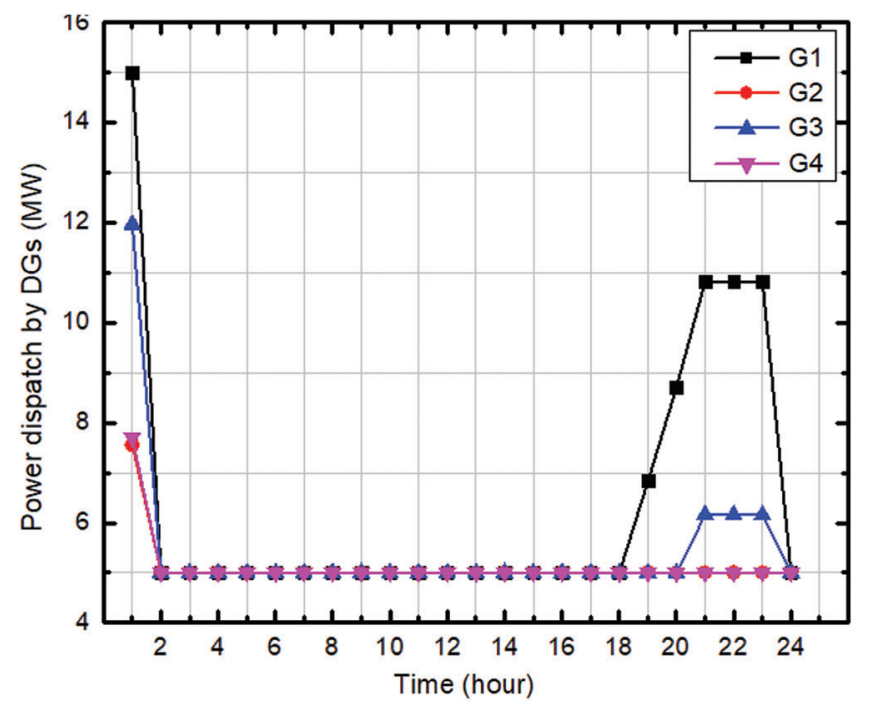

Figure 20: The hourly dispatch of the diesel generators, Al-Khafji

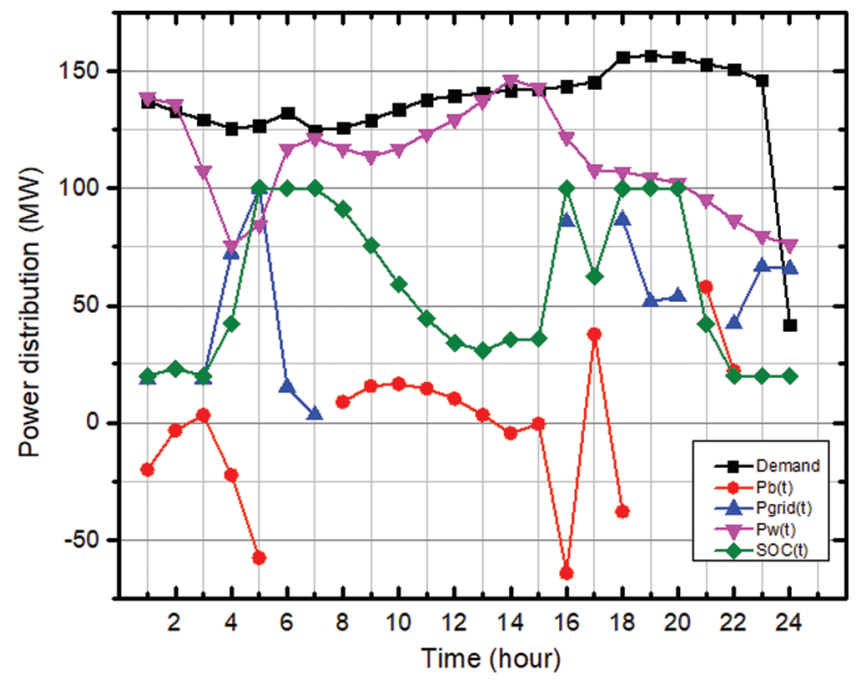

Figure 21: Power distribution in the Scenario I, Al-Khafji

\section{Comparison of Results of Three Sites}

The results of the power exchanged between the microgrid and the main grid, in all Scenarios, are presented in Fig. 23. The power exchanged is the difference between the power imported to and exported from the main grid. The grid power exchanged is the lowest in Al-Khafji followed by Al-Dhahran and Al-Ahsa (Tab. 5). It is seen that lower power is consumed in Scenario II at all sites with Al-Khafji having the lowest value (Fig. 23), followed by AlDhahran and Al-Ahsa in that order. The results also revealed the impact of wind power variability on the operation of the distributed generation, particularly the BESS. Furthermore, this impact is different at each site due to wind power intermittency level and load variability at each site. This means that, in the modeling of wind farms, it is crucial to study the operation of a microgrid at each site independently.

The wind power potential of each site is different, its impact on the BESS operation must be investigated. This is necessary to ensure that the BESS is not overstressed beyond the permitted operational conditions. Although we have not included extensive study of the BESS operation in this 


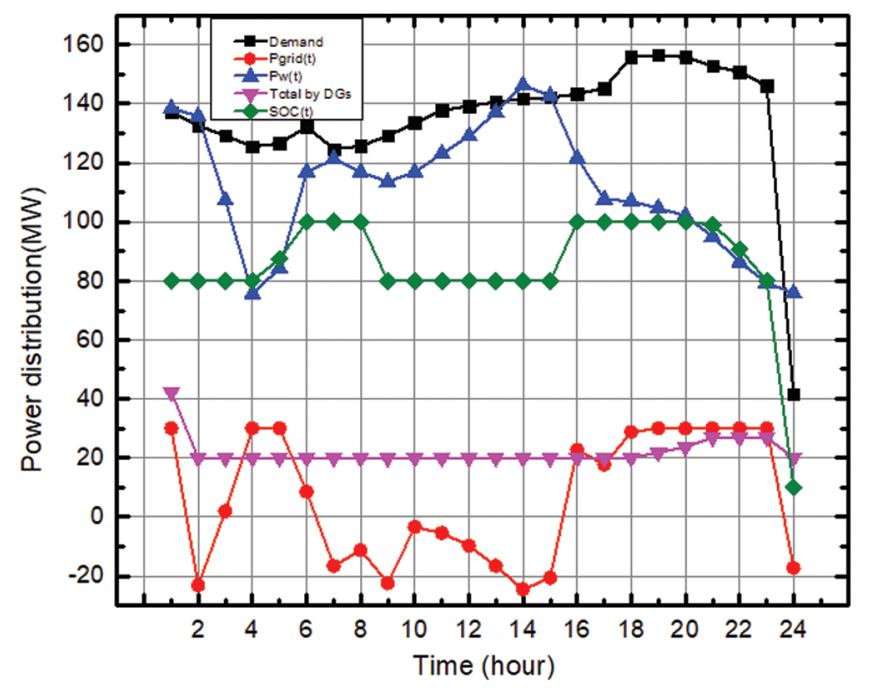

Figure 22: Power distribution in the Scenario II, Al-Khafji

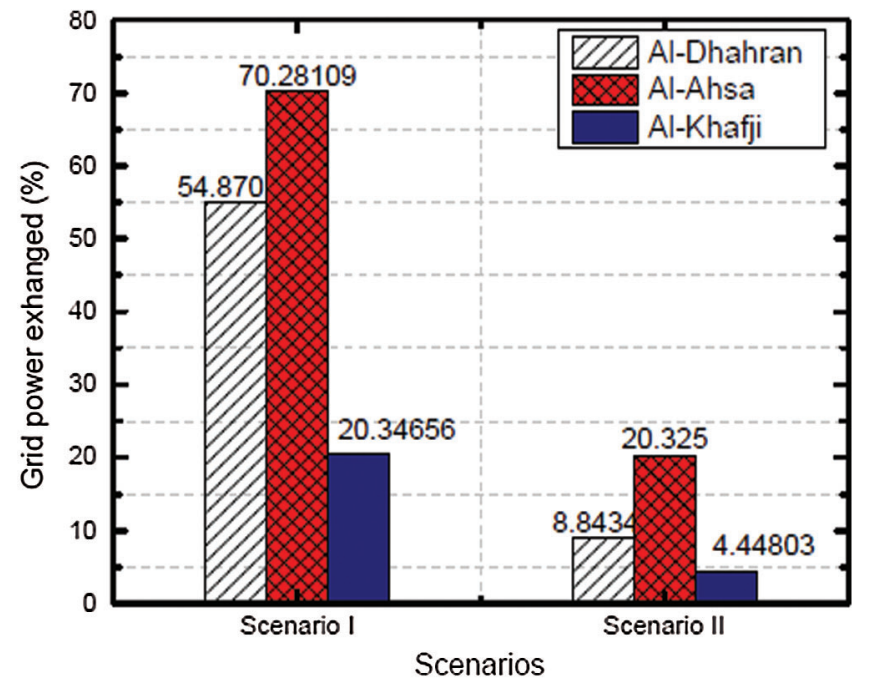

Figure 23: Percentage of the power exchanged with the grid

Table 5: Total power exchanged between the microgrid and the main grid

\begin{tabular}{llll}
\hline Total exchange power with grid (MW) & Al-Dhahran & Al-Ahsa & Al-Khafji \\
\hline Scenario 1 & 1835.69 & 2351.25 & 680.69 \\
Scenario 2 & 295.86 & 679.97 & 148.81 \\
\hline
\end{tabular}

work by considering other BESS parameters. However, the charging/discharging operation and the SOC of the BESS have been thoroughly reported with other parameters like battery aging, depth of discharge, state of health, etc., and can be inferred as described in [32,33]. Moreover, the results summarized in Tabs. 1 to 5 and Fig. 23 reflect the overall quantitative responses of the microgrid to the demand, power exchange, and dynamic pricing. It could be observed that power exchanged and costs vary across all Scenarios and at all the sites. Thus, one can adequately decide when and what amount of grid power should be allowed to 
support a microgrid under each Scenario. Besides, observations from Figs. 8, 16, and 20 give an insight into the optimal number of diesel generators to be installed. For instant, Fig. 20 suggests that lesser number of generators can adequately support the microgrid in Al-Khafji while Figs. 8 and 16 show that numbers of generators chosen for the respective sites are optimal.

Finally, the LPSP for all Scenarios is presented in Tab. 6. Here, the LPSP indicates a measure of reliability and accuracy of the simulations in this study. The values LPSP obtained in all Scenarios are lower, significantly less than 0.1 . This means that the modeling is reliable at its best and very unlikely result in loss of power. Moreover, it is observed that the Al-Khafji site produced the least LPSP (less than $1 \%$ ) compared to others in both Scenarios indicating a high-reliability effect on the microgrid system due to large abundance of wind power at the site. On the other hand, the values of LPSP in Al-Asha are slightly higher (above 10\%) compared to other sites. This reflects the impact of lower wind power availability at the Al-Ahsa. The average LPSP for all Scenarios is less than $10 \%$ indicating the effectiveness of the results. Note that the SOC and other parameters of the BESS used in this study are shown in Tab. 7 while the parameters of the diesel generators are shown in Tab. 8.

Table 6: Total power exchanged between the microgrid and the main grid

\begin{tabular}{llll}
\hline Power loss probability & Al-Dhahran & Al-Ahsa & Al-Khafji \\
\hline Scenario1 & 0.0736 & 0.101 & 0.000 \\
Scenario 2 & 0.093 & 0.198 & 0.003 \\
\hline
\end{tabular}

Table 7: Parameters of the BESS

\begin{tabular}{lllll}
\hline $\mathrm{SOC}_{\max }$ & $\mathrm{SOC}_{\min }$ & $\mathrm{SOC}_{\max }$ & BESS Investment cost & $\mathrm{P}_{\mathrm{bmax}}$ \\
\hline $100 \mathrm{MWh}$ & $10 \%$ & $100 \%$ & $\$ 23000$ & $90 \mathrm{MW}$ \\
\hline
\end{tabular}

Table 8: Generator constants

\begin{tabular}{llllllll}
\hline Unit & $\begin{array}{l}\mathrm{a} \\
\left(\$ / \mathrm{MW}^{2}\right)\end{array}$ & $\begin{array}{l}\mathrm{b} \\
(\$ / \mathrm{MMW})\end{array}$ & $\mathrm{c}$ & $\begin{array}{l}\mathrm{P}_{\min } \\
(\mathrm{MW})\end{array}$ & $\begin{array}{l}\mathrm{P}_{\max } \\
(\mathrm{MW})\end{array}$ & $\begin{array}{l}\mathrm{RU} \\
(\mathrm{MW})\end{array}$ & $\begin{array}{l}\mathrm{RD} \\
(\mathrm{MW})\end{array}$ \\
\hline 1 & 0.12 & 14.8 & 89 & 10 & 50 & 10 & 10 \\
2 & 0.17 & 16.57 & 83 & 10 & 60 & 12 & 10 \\
3 & 0.15 & 15.55 & 100 & 20 & 50 & 10 & 10 \\
4 & 0.19 & 16.21 & 70 & 10 & 40 & 8 & 8 \\
\hline
\end{tabular}

\section{Conclusions}

In this study, an energy management strategy for windfarm distributed generation is presented. Two Scenarios, a wind-based grid-connected microgrid supported with BESS and a grid-connected wind-based microgrid supplemented with diesel generators in addition to BESS, are presented. By utilizing the GAMS simulation software, the cost of operation of the microgrids was computed for the two Scenarios considering the wind power generation potential at three sites. Simulations showed that the adopted method gives optimal energy management, ensuring that the wind power is efficiently utilized and BESS is operated optimally in all Scenarios. Besides, the method ensures an optimal power exchange between the microgrid and the main grid. 
The study revealed the highest wind power potential is from the wind farm in Al-Khafji support the proposed type of microgrid. It was found that it is cheaper to operate the microgrid in Al-Khafji than the ones in Al-Dhahran and Al-Ahsa. The minimum optimal operation costs are obtained in each of the Scenarios underscore the outcomes of the study. The results from Al-Khafji site gives the minimum costs and allow better operation of the distributed generators. This means, that the modeling is reliable and very unlikely to result in loss of power. Moreover, it is observed that the LPSP recorded in all Scenario yield a good performance with the Al-Khafji site producing the best LPSP (less than 1\%).

Therefore, the results in Scenario II of this study infer that a good amount of money could be saved in the operation of a large wind power generation, if the proposed approach is considered.

In the future, it will be interesting to look at the comprehensive planning of a large wind farm while considering parameters such as investment cost, lifecycle cost, and degradation of the distributed generators. The other parameters of the BESS such as depth of discharge and state of health can also be adequately studied.

Funding Statement: This work was supported by the Deanship of Research at King Fahd University of Petroleum \& Minerals, Dhahran-31261, Saudi Arabia, under project number SB181005.

Conflicts of Interest: The authors declare that they have no conflicts of interest to report regarding the present study.

\section{References}

1. World Wind Energy Association (WWEA) (2019). Wind energy report 2019. Online kernel description, https:// wwindea.org/blog/2019/02/25/wind-power-capacity-worldwide-reaches-600-gw-539-gw-added-in-2018/.

2. Shafiee, S., Topal, E. (2009). When will fossil fuel reserves be diminished? Energy Policy, 37(1), 181-189. DOI 10.1016/j.enpol.2008.08.016.

3. Mohammad, A. S., Sami, A. K. (2018). Transition towards sustainable energy production-a review of the progress for solar energy in Saudi Arabia. Energy Exploration \& Exploitation, 36(1), 3-27. DOI 10.1177/ 0144598717737442.

4. Al-Ajlan, S. A., Al-Ibrahim, A. M., Abdulkhaleq, M., Alghamdi, F. (2006). Developing sustainable energy policies for electrical energy conservation in Saudi Arabia. Energy Policy, 34(13), 1556-1565. DOI 10.1016/j. enpol.2004.11.013.

5. Makbul, A. M., Twaha, R. S., Al-Hamouz, Z. (2017). Analyzing the potential and progress of distributed generation applications in Saudi Arabia: the case of solar and wind resources. Renewable and Sustainable Energy Reviews, 70, 287-297. DOI 10.1016/j.rser.2016.11.204.

6. Allhibi, H., Chowdhury, H., Zaid, M., Loganathan, B., Alam, F. (2018). Prospect of wind energy utilization in Saudi Arabia: a review. Energy Procedia, 160, 746-751. 2nd International Conference on Energy and Power, pp. 13-15 December, Sydney, Australia.

7. Matar, W., Anwer, M. (2017). Jointly reforming the prices of industrial fuels and residential electricity in Saudi Arabia, Energy Policy, 109, 747-756.

8. Bouzidi, L., Bellaaj, N., Euch, M. E. (2015). Large scale wind power integration: extended power system operations. Saudi Arabia Smart Grid, Jeddah, 1-6.

9. Rehman, S., El-Amin, I. M., Shaahid, S., Ahmad, A., Ahmad, F. et al. (2007). Wind measurements and energy potential for a remote village in Saudi Arabia. IEEE Power Engineering Society Conference and Exposition in Africa-PowerAfrica, Johannesburg, 1-5.

10. Shahrani, S. A., Khedair, A. A. (2015). Integrated wind-solar power generation system for national guard facility, Saudi Arabia Smart Grid, pp. 1-5.

11. Aljahdali, F., Abbod, M. (2018). Design of smart generation by integrating renewable energy into western power grid of Saudi Arabia. 53rd International Universities Power Engineering Conference, Glasgow, pp. 1-6. 
12. Rehman, S., El-Amin, I. M. (2010). Study of a standalone wind and solar PV power systems. IEEE International Energy Conference, Manama, pp. 228-232.

13. Khalid, M., Al-Muhaini, M., Aguilera, R. P., Savkin, A. V. (2018). Method for planning a wind-solar-battery hybrid power plant with optimal generation-demand matching. IET Renewable Power Generation, 12(15), 1800-1806. DOI 10.1049/iet-rpg.2018.5216.

14. Yasin, J. A., Alghamdi, M., Schulze, F. H., Provenzano, D., Hassan, A. (2017). RES impact study in the Northern Region of KSA: first step toward energy diversification ion. Saudi Arabia Smart Grid, Saudi Arabia, pp. 1-7.

15. Alismail, F., Xiong, P., Singh, C. (2018). Optimal wind farm allocation in multi-area power systems using distributionally robust optimization approach. IEEE Transactions on Power Systems, 33(1), 536-544. DOI 10.1109/TPWRS.2017.2695002.

16. Salman, U. T., Khalid, M., Al-Ismail, F. (2020). Optimal energy management strategy based on dynamic energy dispatch for a wind-penetrated microgrid (ICREPQ2020), Granada, Spain.

17. Akram, U., Khalid, M., Shafiq, S. (2018). Optimal sizing of a wind/solar/battery hybrid grid-connected microgrid system. IET Renewable Power Generation, 12(1), 72-80. DOI 10.1049/iet-rpg.2017.0010.

18. Twaha, S., Al-Hamouz, Z., Mukhtiar, M. U. (2014). Optimal hybrid renewable-based distributed generation system with feed-in tariffs and ranking technique. IEEE 8th International Power Engineering and Optimization Conference, Langkawi, pp. 115-120.

19. Eroshenko, S. A., Samoylenko, V. O., Pazderin, A. V. (2016). Renewable energy sources for perspective industrial clusters development. 2nd International Conference on Industrial Engineering, Applications and Manufacturing (ICIEAM), Chelyabinsk, 1-5.

20. Elhadidy, M. A., Shaahid, S. M. (2007). Wind resource assessment of eastern coastal region of Saudi Arabia. Desalination, 209, 199-208. The Ninth Arab International Conference on Solar Energy (AICSE-9), Kingdom of Bahrain. ISSN: 0011-9164. http://www.sciencedirect.com/science/article/pii/S0011916407001208.

21. Şahin, A. Z, Aksakal, A. (1998). Wind power energy potential at the northeastern region of Saudi Arabia. Renewable Energy, 14(1), 435-440. 6th Arab International Solar Energy Conference: Bringing Solar Energy into the Daylight. ISSN: 0960-1481. http://www.sciencedirect.com/science/article/pii/S0960148198001001.

22. Al-Abbadi, N. M. (2005). Wind energy resource assessment for five locations in Saudi Arabia. Renewable Energy, 30(10), 1489-1499. ISSN: 0960-1481. http://www.sciencedirect.com/science/article/pii/S0960148104004227.

23. Rehman, S., Al-Abbadi, N. M. (2008). Wind shear coefficient, turbulence intensity and wind power potential assessment for Dhulom, Saudi Arabia. Renewable Energy, 33(12), 2653-2660. ISSN: 0960-1481. http://www. sciencedirect.com/science/article/pii/S0960148108000529.

24. Rehman, S., Halawani, T. O., Mohandes, M. (2003). Wind power cost assessment at twenty locations in the Kingdom of Saudi Arabia. Renewable Energy, 28(4), 573-583. DOI 10.1016/S0960-1481(02)00063-0.

25. Rehman, S., Ahmad, A. (2004). Assessment of wind energy potential for coastal locations of the Kingdom of Saudi Arabia. Energy, 29(8), 1105-1115. DOI 10.1016/j.energy.2004.02.026.

26. Rehman, S., El-Amin, I. M., Ahmad, F., Shaahid, S. M., Al-Shehri, A. M. et al. (2007). Wind power resource assessment for Rafha, Saudi Arabia. Renewable and Sustainable Energy Reviews, 11(5), 937-950. ISSN: 13640321. http://www.sciencedirect.com/science/article/pii/S1364032105000717.

27. Atherton, J., Sharma, R., Salgado, J. (2017). Techno-economic analysis of energy storage systems for application in wind farms. Energy, 135, 540-552. DOI 10.1016/j.energy.2017.06.151.

28. Wilson, A., Webster, R., Hayes, B. P., Djokic, S. Z. (2016). Comparison of two energy storage options for optimum balancing of wind farm power outputs. IET Generation, Transmission \& Distribution, 10(3), 832-839. DOI 10.1049/iet-gtd.2015.0486.

29. Song, Z., Feng, S., Zhang, L., Hu, Z., Hu, X. et al. (2019). Economy analysis of second-life battery in wind power systems considering battery degradation in dynamic processes: real case scenarios. Applied Energy, 251, 113411. DOI 10.1016/j.apenergy.2019.113411.

30. Salman, U. T., Al-Ismail, F., Khalid, M. (2020). Optimal sizing of battery energy storage for grid-connected and isolated wind-penetrated microgrid. IEEE Access, 8, 91129-91138. 
31. Phan, Q. A., Scully, T., Breen, M., Murphy, M. D. (2018). Determination of optimal battery utilization to minimize operating costs for a grid-connected building with renewable energy sources. Energy Conversion and Management, 174, 157-174. DOI 10.1016/j.enconman.2018.07.081.

32. Salman, U. T., Abdulgalil, M. A., Wasiu, O. S., Khalid, M. (2019). Energy management strategy considering battery efficiency for grid-tied microgrids during summer in the kingdom of Saudi Arabia. 2019 International Conference on Renewable Energy Research and Applications, Brasov, Romania, IEEE, pp. 730422-730427.

33. Luu Ngoc, A., Tran Quoc, T. (2015). Optimal energy management for grid connected microgrid by using dynamic programming method. IEEE Power \& Energy Society General Meeting, Denver, 1-5.

34. Murnane, M., Ghazel, A. (2017). A closer look at state of charge (soc) and state of health (soh) estimation techniques for batteries. Analog Devices, 2, 426-436.

35. Babazadeh, H., Gao, W., Wu, Z., Li, Y. (2013). Optimal energy management of wind power generation system in islanded microgrid system. North American Power Symposium, Manhattan, 1-5.

36. Meng, L., Dragicevic, T., Vasquez, J. C., Guerrero, J. M. (2015). Tertiary and secondary control levels for efficiency optimization and system damping in droop-controlled dc-dc converters. IEEE Transactions on Smart Grid, 6(6), 2615-2626. DOI 10.1109/TSG.2015.2435055.

37. Matar, W., Anwer, M. (2017). Reforming Industrial Fuel Price and Residential Electricity Price in Saudi Arabia kernel description, K2017-DP018-Reforming-Industrial-Fuel-and-Residential-Electricity-Prices-i-SaudiArabia, September 2017.

38. Tran, Q., Luu, N. A., Nguyen, T. L. (2016). Optimal energy management strategies of microgrids. IEEE Symposium Series on Computational Intelligence, Athens, 1-6. DOI 10.1109/SSCI.2016.7849851.

39. Sufyan, M., Abd Rahim, N., Tan, C. K., Muhammad, M. A., Sheikh Raihan, S. R. et al. (2019). Optimal sizing and energy scheduling of isolated microgrid considering the battery lifetime degradation. PLoS One, 14(2), e0211642. DOI 10.1371/journal.pone.0211642.

40. Ju, C., Wang, P., Goel, L., Xu, Y. (2017). A two-layer energy management system for microgrids with hybrid energy storage considering degradation costs. IEEE Transactions on Smart Grid, 9(6), 6047-6057. DOI 10.1109/TSG.2017.2703126.

41. Ayop, R., Isa, N. M., Tan, C. W. (2018). Components sizing of photovoltaic stand-alone system based on loss of power supply probability. Renewable and Sustainable Energy Reviews, 81, 2731-2743. DOI 10.1016/j. rser.2017.06.079.

42. McEvoy, A., Markvart, T., Castañer, L., Markvart, T., Castaner, L. (2003). Practical handbook of photovoltaics: fundamentals and applications. Glasgow United Kingdom: Elsevier. 